IP Periodica Polytechnica

Mechanical Engineering

62(3), pp. 196-202, 2018

https://doi.org/10.3311/PPme.11347

Creative Commons Attribution (i)

RESEARCH ARTICLE

\section{Numerical Modelling and Optimization of Dry Orthogonal Turning of Al6061 T6 Alloy}

\author{
Chathakudath Sukumaran Sumesh ${ }^{1 *}$, Ajith Ramesh ${ }^{1}$
}

Received 10 August 2017; accepted 16 February 2018

\begin{abstract}
In this paper, the influence of machining parameters, Cutting Speed, Feed Rate, and Depth of cut, on surface finish during dry orthogonal turning of Al 6061 - T6 alloy, is studied using the response surface methodology (RSM). This paper proposes a unique way to predict the surface finish in turning, using the effective plastic strain (PEEQ) values obtained from the simulations. A comprehensive finite element model was proposed to predict the surface finish accurately, by correlating the variance of the PEEQ. The Johnson-Cook damage model is used to define the damage criteria and Johnson-Cook material model is used to explain the material constitutive behavior. A dynamic, explicit method is used along with the Adaptive LagrangianEulerian (ALE) method to predict material flow accurately. The influence of machining parameters was studied by assuming Central Composite Design (CCD). The output response, PEEQ, was fitted into analytical quadratic polynomial models using regression analysis, which shows that feed rate was the most dominant factor for PEEQ than the other parameters considered in this study. Using the individual desirability function method, the objective, optimal setting of the machining parameters was obtained for better surface finish.
\end{abstract}

\section{Keywords}

orthogonal turning, RSM, PEEQ, JC model, ALE, CCD

\footnotetext{
${ }^{1}$ Department of Mechanical Engineering, Amrita School of Engineering, Coimbatore, Amrita Vishwa Vidyapeetham, India

*Corresponding author, e-mail: cs_sumesh@cb.amrita.edu
}

\section{Introduction}

Aluminum compounds are among the most critical metals in industries. The Al 6061-T6 aluminum composite is an exceptionally significant alloy because of its prevailing mechanical properties, for example, weldability, hardness, and manageability at high temperatures. Al 6061-T6 is generally used in heavy industries including aviation, flying machine, car, and so on. Turning of Al 6061-T6 composite is imperative, particularly to make parts shape varieties for various applications. Al 6061 alloy is generally utilized for commercial applications in the aviation, car parts development, and designing industries.

Somashekara and Swamy [1] determined the optimum conditions for surface roughness during turning Al 6351 - T6 alloy using regression technique. Rajpoot et al. [2] studied the influence of cutting parameters on material removal rate and surface roughness while turning of Al 6061 ally using RSM. Hasçalık and Çaydaş [3] studied effect and optimization of machining parameters on surface roughness and tool life in a turning operation was investigated by using the Taguchi method. Lodhi and Shukla [4] optimized the surface roughness and MRR during machining of AISI 1018 alloy with Titanium coated Carbide inserts using Taguchi method. Choudhury and El-Baradie [5] developed a surface roughness prediction model using the factorial design of experiments in turning of high strength steel. Suresh et al. [6] developed a model to predict the surface roughness using RSM while machining mild steel by TiC-coated tungsten carbide (CNMG) cutting tools. Nalbant et al. [7] applied Taguchi method for optimizing the machining parameters for surface roughness while turning. They concluded that the insert radius and feed rate are the main parameters that influence the surface roughness in turning.

\section{Experimental Details}

Using the conventional lathe, a dry hard turning of Al6061 - T6 alloy was performed. Specimens of size $20 \mathrm{~mm}$ diameter and $150 \mathrm{~mm}$ long used for the experimental study. The tool used is having a rake angle $0^{\circ}$ and a clearance angle of $6^{\circ}$ was used. The selected machining parameters and their three levels are shown in Table 1. 
Using Central Composite Design (CCD), under the Response Surface Methodology (RSM), available in the software, possible 20 combinations of the selected parameters were obtained. Since, experimental approach is costly as well as time - consuming and difficult, dry hard orthogonal turning operation was carried out only for certain combinations. Then, the surface finish of the machined surfaces was taken using the handy surf - surface roughness tester.

Table 1 Three levels of selected machining parameters.

\begin{tabular}{lcccc}
\hline $\begin{array}{l}\text { Machining } \\
\text { Parameters }\end{array}$ & Symbol & Level 1 & Level 2 & Level 3 \\
\hline Cutting Speed (rpm) & V & 630 & 1115 & 1600 \\
Feed rate (mm/min) & $\mathrm{f}$ & 0.08 & 0.12 & 0.16 \\
Depth of cut (mm) & $\mathrm{d}$ & 0.5 & 1.0 & 1.5 \\
\hline
\end{tabular}

\section{Finite Element Modelling of Orthogonal Turning Process}

In this study, commonly used finite element software, ABAQUS/Explicit, was used. A 2D numerical model was made to simulate the orthogonal process and the model was used to predict the effects of selected machining parameters on the surface finish, during the turning process of Al6061 - T6 alloy. The workpiece is created as deformable whereas tool is made as analytical rigid. The clearance angle and rake angle of the tool are assumed to be constant as $6^{\circ}$ and $0^{\circ}$ respectively. The finite element model of the $2 \mathrm{D}$ orthogonal cutting is shown in Fig. 1, where $\mathrm{h}$ represents the height of the work piece, $\mathrm{w}$ represents the length of the work piece, and doc represents the depth of cut. In this FE model, Johnson Cook (JC) material model was used to describe the material constitutive behaviour and is represented by Eq. (1). The equation describes the stress - strain behaviour of the material, under the effects of thermal softening, strain hardening, and strain rate hardening.

$$
\bar{\sigma}=\left[A+B\left(\bar{\varepsilon}_{p l}\right)^{n}\right]\left[1+C \ln \left(\frac{\dot{\dot{\varepsilon_{p l}}}}{\dot{\varepsilon_{0}}}\right)\right]\left[1-\left(\frac{T-T_{\text {room }}}{T_{\text {melt }}-T_{\text {room }}}\right) m\right]
$$

where $\bar{\sigma}$ is the equation flow stress, $\overline{\varepsilon_{p l}}$ is the equivalent plastic strain, $\overline{\varepsilon_{p l}}$ equivalent plastic strain rate, $\dot{\varepsilon}_{0}$ is the reference equivalent plastic strain rate. $\mathrm{T}$ is the temperature of the work piece, $\mathrm{T}_{\text {melt }}$ is the melting temperature of the work piece material, and $\mathrm{T}_{\text {room }}$ is the room temperature. $\mathrm{A}$ is the initial yield strength of the material at room temperature, $\mathrm{B}$ represents the hardening modulus, $\mathrm{C}$ is the coefficient dependent on the strain rate, $\mathrm{n}$ is the work hardening exponent and $\mathrm{m}$ is the thermal softening. Table 3, shows the JC material model parameters used in the study.

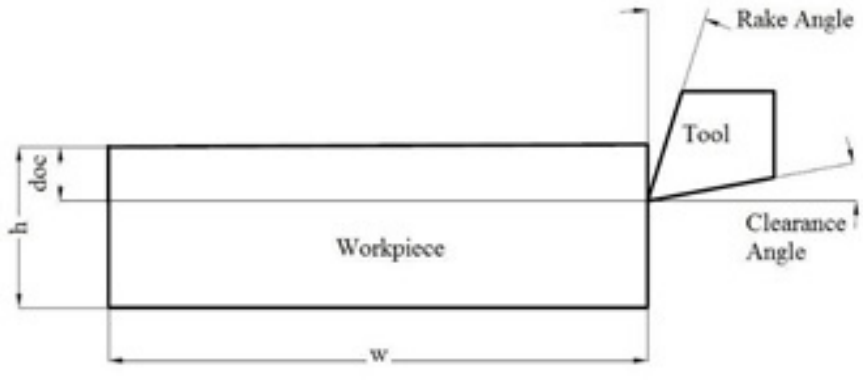

Fig. 1 2D FE model of Orthogonal Turning

Table 2 Mechanical and Thermal properties of Al6061 - T6 alloy.

\begin{tabular}{ccc}
\hline & Mechanical & \\
\hline Density & Young's Modulus & Poisson's Ratio \\
$2700 \mathrm{Kg} / \mathrm{m}^{3}$ & $68.9 \mathrm{GPa}$ & 0.33 \\
\hline & Thermal & \\
\hline Conductivity & Specific heat & Coe. of linear exp. \\
$167 \mathrm{~W} / \mathrm{mK}$ & $0.896 \mathrm{~J} / \mathrm{g}^{\circ} \mathrm{C}$ & $23.6 \mathrm{E}-6 /{ }^{\circ} \mathrm{C}$ \\
\hline
\end{tabular}

Table 3 Johnson Cook Material Model Parameters.

\begin{tabular}{ccccccc}
\hline $\mathrm{A}(\mathrm{MPa})$ & $\mathrm{B}(\mathrm{MPa})$ & $\mathrm{C}$ & $\mathrm{n}$ & $\mathrm{m}$ & $\mathrm{T}_{\text {room }}\left({ }^{\circ} \mathrm{C}\right)$ & $\mathrm{T}_{\text {melt }}\left({ }^{\circ} \mathrm{C}\right)$ \\
\hline 324.1 & 113.8 & 0.002 & 0.42 & 1.34 & 25 & 652 \\
\hline
\end{tabular}

In the finite element model, a ductile damage energy based criterion was applied. Eq. (2) represents the expression, according to JC damage criterion, for the fracture strain.

$$
\begin{aligned}
& \bar{\varepsilon}_{\text {oi }}{ }^{f}=\left(D_{1}+D_{2} \exp D_{3} \frac{\sigma_{m}}{\bar{\sigma}}\right)\left(1+D_{4} \ln \left(\frac{\dot{\dot{\varepsilon_{p l}}}}{\dot{\dot{\bar{\varepsilon}}}}\right)\right) \\
& {\left[1+D_{5}\left(\frac{T-T_{\text {room }}}{T_{\text {melt }}-T_{\text {room }}}\right)\right]}
\end{aligned}
$$

where, $D_{1}$ is initial failure strain, $D_{2}$ is the exponential factor, $D_{3}$ is triaxiality factor, $\mathrm{D}_{4}$ is the strain rate factor, $\mathrm{D}_{5}$ is temperature factor, $\bar{\varepsilon}_{o i}{ }^{f}$ is the equivalent plastic strain at fracture initiation, $\sigma_{m}$ is the means stress and $\bar{\sigma}$ is the von Mises equivalent stress. The JC damage parameters used in this study are given in Table 4.

Table 4 Johnson Cook Damage Model Parameters.

\begin{tabular}{ccccc}
\hline D1 & D2 & D3 & D4 & D5 \\
\hline-0.77 & 1.45 & 0.47 & 0.0 & 1.6 \\
\hline
\end{tabular}

The mesh quality is maintained throughout the simulation using the Arbitrary Lagrangian Eulerian (ALE) meshing technique. Using ALE, the mesh is not attached to the material and can be moved arbitrarily. The mesh is deformed continuously to optimize element shapes independently from material deformation [8]. Fig. 2 shows the regions of application of ALE in the current study. Marimuthu et. al. [9], developed a numerical model to predict the residual stress during the multiple passes 
turning of AISI 4340 steel using ALE approach. In the present study, constant friction coefficient $(\mu=0.24)$ was assumed.

An encastre boundary condition was applied to the lower edge and to the left edge of the workpiece. A calculated value for velocity was assigned to the reference point on the tool along the negative $\mathrm{x}$-direction as the boundary condition. Also, the vertical displacement of the tool is constrained (see Fig. 2). Plane strain element type, CPE4RT elements, are used in the model. Numerical simulations were carried out for the same combinations, on which experiments were done and correlated the FE model results by comparing the values with experimental results. The main challenge faced in the numerical model was the penetration of the chip into the work piece. To tackle this, a self-contact algorithm suggested by Ramesh et al. [10] was used in the model.

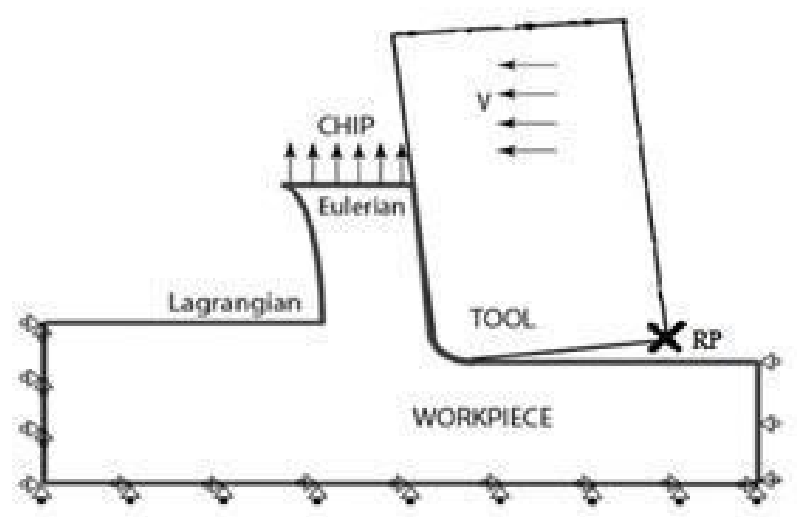

Fig. 2 Adaptive Lagrangian Eulerian method used

For the purpose of understanding, the effect of selected machining parameters on surface finish, the variance of equivalent plastic strain was used as the output response function. Equivalent plastic strain (PEEQ) represents the effective plastic strain or enduring distortion, a material experiences due to the action of an external force. In any manufacturing processes, the effective plastic strains are randomly distributed on the machined surface of the workpiece. From this uneven distribution, the profile of crests and troughs can be measured on the surface. The mean value of PEEQ, obtained at the integration points on the workpiece surface, was calculated. Thus the variance of PEEQ is evaluated, which can be used as an indication of surface roughness. Chen et al. [11] and Ducobu et al. [12], validated the concept, of using the PEEQ for enumerating the surface finish of the machined workpiece by simulations and experiments. Better the surface finish, if the variance of PEEQ value decreases.

Fig. 3(a) shows the variation of surface roughness with cutting speed (from the experiments) and Fig. 3(b) shows the deviation of surface roughness with cutting speed (from the simulations) when feed rate, $\mathrm{f}=0.12 \mathrm{~mm} / \mathrm{min}$ and depth of cut, $\mathrm{d}=$ $1 \mathrm{~mm}$. Both the figures are having the same trend and the ratios of values are almost matching with each other. Hence, PEEQ can be used as a favourable assessment method for predicting surface finish.
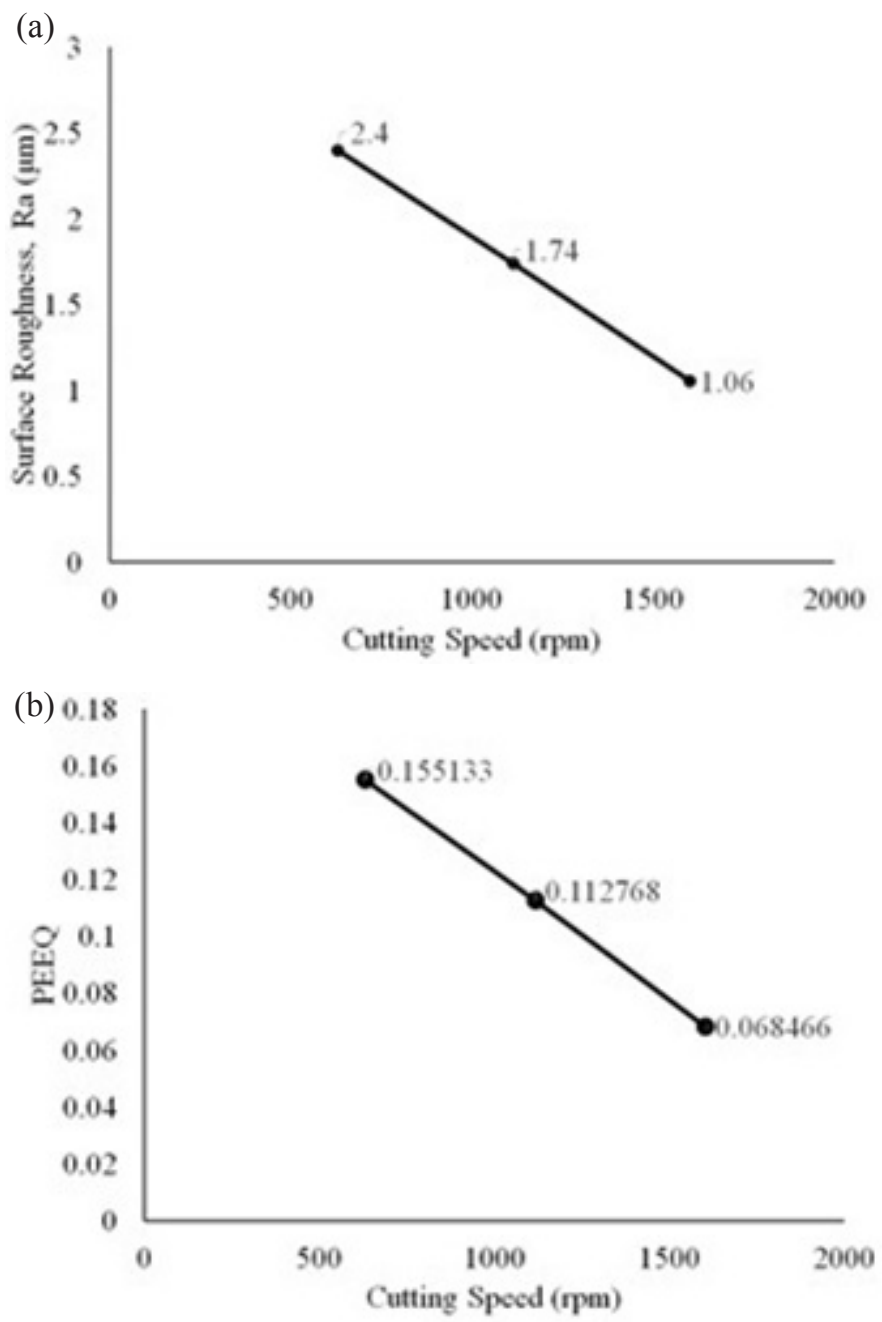

Fig. 3 Validation of (a) Experimental and (b) Simulation results

\section{Results and Discussions}

The three levels of selected machining parameters input into Minitab software and the 20 possible trials or combinations were obtained. The most commonly used response surface designed experiment, Central Composite Design (CCD) method was used in this study. Face centered designs, a type of CCD, was used in the present study to obtain the levels between low and high values of parameters. Simulations were run in the validated model and obtained the variance of PEEQ. These simulation results are tabulated in Table 5. Then the quadratic model was obtained, based on the 20 PEEQ values from the simulations, to predict the values of response and graphical correlation of predicted and simulated values was made. The quadratic model derived for PEEQ from RSM, is shown in Eq. (3).

$$
\begin{aligned}
& P E E Q=-0.223+0.000039 V+5.09 f-0.003 d-0.000001 V^{2} \\
& -21.16 f^{2}-0.0192 d^{2}-0.000091 V f-0.000028 V d+0.487 f d
\end{aligned}
$$


Table 5 Simulation results of PEEQ

\begin{tabular}{|c|c|c|c|c|}
\hline $\begin{array}{l}\text { Trail } \\
\text { No. }\end{array}$ & $\begin{array}{c}\text { Cutting Speed, } \\
\text { V (rpm) }\end{array}$ & $\begin{array}{l}\text { Feed rate, } f \\
(\mathrm{~mm} / \mathrm{min})\end{array}$ & $\begin{array}{l}\text { Depth of cut, } \\
\text { d (mm) }\end{array}$ & PEEQ \\
\hline 1 & 1600 & 0.16 & 0.5 & 0.094159 \\
\hline 2 & 1115 & 0.12 & 1 & 0.112768 \\
\hline 3 & 1115 & 0.12 & 1 & 0.112768 \\
\hline 4 & 1600 & 0.16 & 1.5 & 0.092165 \\
\hline 5 & 1115 & 0.08 & 1 & 0.070139 \\
\hline 6 & 1600 & 0.08 & 0.5 & 0.090545 \\
\hline 7 & 630 & 0.08 & 1.5 & 0.042546 \\
\hline 8 & 1115 & 0.12 & 1 & 0.112768 \\
\hline 9 & 1600 & 0.08 & 1.5 & 0.032994 \\
\hline 10 & 1115 & 0.12 & 0.5 & 0.103487 \\
\hline 11 & 1115 & 0.12 & 1.5 & 0.122678 \\
\hline 12 & 630 & 0.12 & 1 & 0.155133 \\
\hline 13 & 630 & 0.16 & 0.5 & 0.083493 \\
\hline 14 & 1600 & 0.12 & 1 & 0.068466 \\
\hline 15 & 630 & 0.16 & 1.5 & 0.092199 \\
\hline 16 & 1115 & 0.12 & 1 & 0.112768 \\
\hline 17 & 1115 & 0.12 & 1 & 0.112768 \\
\hline 18 & 1115 & 0.12 & 1 & 0.112768 \\
\hline 19 & 630 & 0.08 & 0.5 & 0.056271 \\
\hline 20 & 1115 & 0.16 & 1 & 0.087904 \\
\hline
\end{tabular}

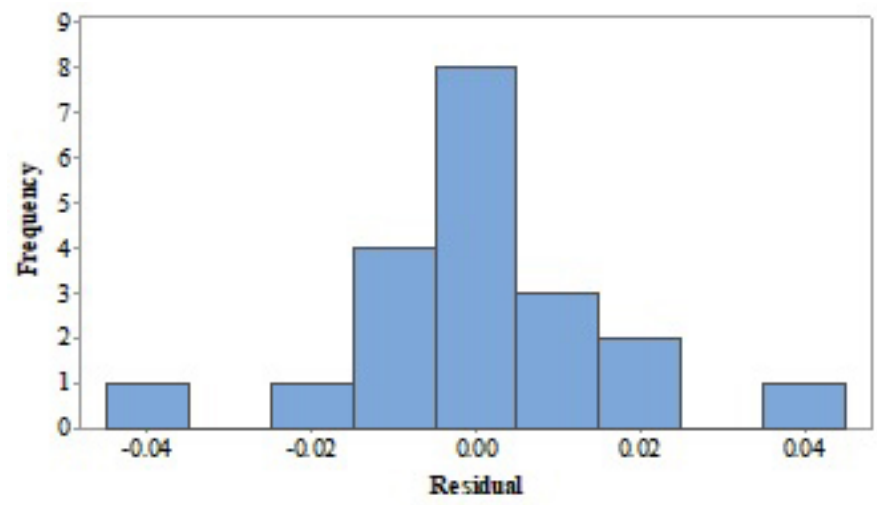

(a)
In order to study the extent to which the simulated results matches with the RSM values, residual plots are drawn. The quadratic model was obtained based on the method of least squares, with some assumptions. The histogram of the residuals shown in Fig. 4(a), displays the distribution of the residuals for all PEEQ values. The histogram of residuals recommends that the residuals are normally distributed, with one extreme outlier. Using the normal probability plot of residuals shown in Fig. 4(b) shows that the relationship between the theoretical percentiles and the residuals is approximately linear. Thus, the normal probability plot of the residuals proposes that the error terms are definitely normally distributed. The residuals versus order plot, shown in Fig. 4(c), to verify the assumption that the residuals are independent of one another.

Using the regression equation (3), the predicted values of PEEQ was obtained for different values of machining parameters and consequently related with the corresponding simulation values.

\subsection{Influence of machining parameters on response PEEQ}

Table 6 shows the ANOVA results for full quadratic model for PEEQ. Initial analysis of variance (ANOVA) with full model, including linear, square and interaction terms, was performed for the response, PEEQ. In the obtained ANOVA table, the $\mathrm{P}$ values for all the terms are less than 0.05 , means all the

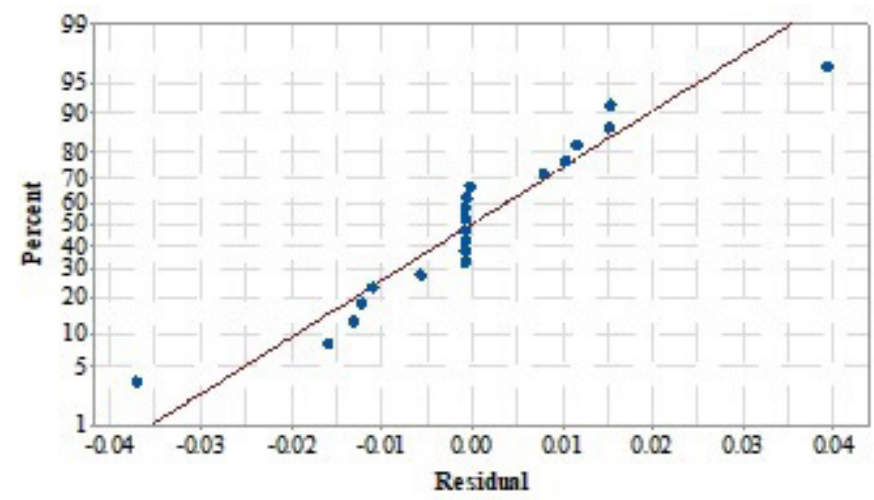

(b)

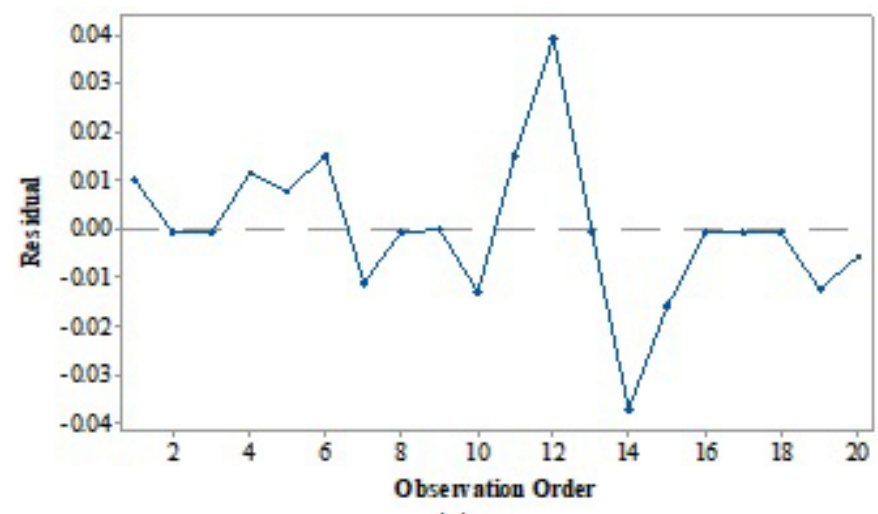

(c)

Fig. 4 Residual plots for PEEQ 
terms are significant. To study the effect of machining parameters $(\mathrm{V}, \mathrm{f}, \mathrm{d})$ on the response, PEEQ, the main effect and interaction effect plots -are prepared. Also, the contour plots and surface plots are obtained.

Table 6 ANOVA results for PEEQ

\begin{tabular}{lccccc}
\hline Source & DF & Adj SS & Adj MS & F-Value & P-Value \\
\hline Model & 9 & 0.011527 & 0.001281 & 3.27 & 0.040 \\
Linear & 3 & 0.003288 & 0.001096 & 2.80 & 0.095 \\
V & 1 & 0.000263 & 0.000263 & 0.67 & 0.0432 \\
$\mathrm{f}$ & 1 & 0.002478 & 0.002478 & 6.32 & 0.031 \\
$\mathrm{~d}$ & 1 & 0.000547 & 0.000547 & 1.39 & 0.0465 \\
Square & 3 & 0.007082 & 0.002361 & 6.02 & 0.013 \\
$\mathrm{~V} * \mathrm{~V}$ & 1 & 0.000003 & 0.000003 & 0.01 & 0.0483 \\
$\mathrm{f} * \mathrm{f}$ & 1 & 0.003153 & 0.003153 & 8.04 & 0.018 \\
$\mathrm{~d} * \mathrm{~d}$ & 1 & 0.000064 & 0.000064 & 0.16 & 0.0496 \\
Interaction & 3 & 0.001157 & 0.000386 & 0.98 & 0.0439 \\
$\mathrm{~V} * \mathrm{f}$ & 1 & 0.000025 & 0.000025 & 0.06 & 0.0499 \\
$\mathrm{~V} * \mathrm{~d}$ & 1 & 0.000372 & 0.000372 & 0.95 & 0.0353 \\
$\mathrm{f} * \mathrm{~d}$ & 1 & 0.000760 & 0.000760 & 1.94 & 0.0394 \\
Pure Error & 5 & 0.000000 & 0.000000 & & \\
Total & 19 & 0.015449 & & & \\
\hline
\end{tabular}

Fig. 5 shows the plot on main effects for PEEQ, it can be seen that the minimum value of PEEQ, i.e. better surface finish is obtained at high values of $\mathrm{V}$, at low values of feed rate and at high values of depth of cut.

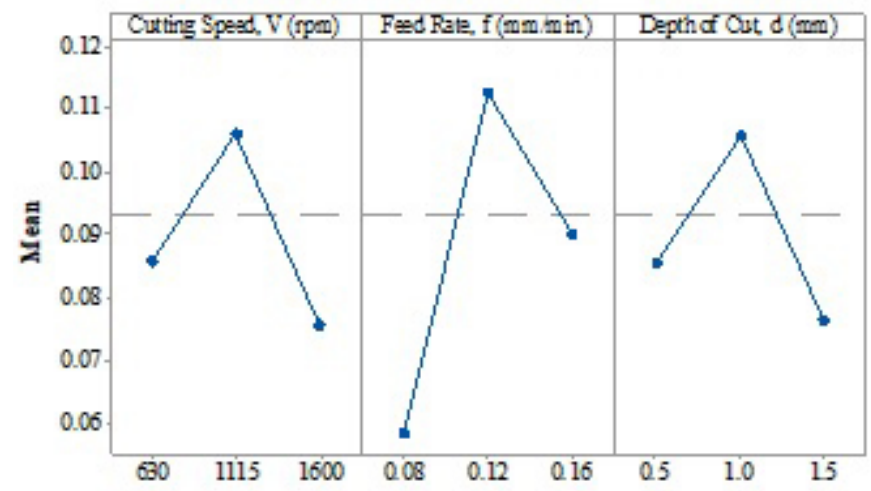

Fig. 5 Main Effect plots of PEEQ

Fig. 6 shows the interaction plots for PEEQ. Each plot exhibits the interaction effect of two different machining parameters on PEEQ. According to Fig. 6, V X f, and V X d have specific interaction exists and has an important effect on PEEQ.

Fig. 7 represents contour and response surface plots for PEEQ in relation to the machining parameters of $f$ and $V$, where $\mathrm{d}$ remains constant at its mean level of $1 \mathrm{~mm}$. PEEQ decreases with decreases in feed rate (f). At low values of feed rate, less volume of material is in contact with the work piece and less force is required to remove the material, which leads to the good surface finish. Therefore, the minimum PEEQ can be seen at a high value of $\mathrm{V}(1600 \mathrm{rpm})$ and low value of $\mathrm{f}(0.08 \mathrm{~mm} / \mathrm{min})$.
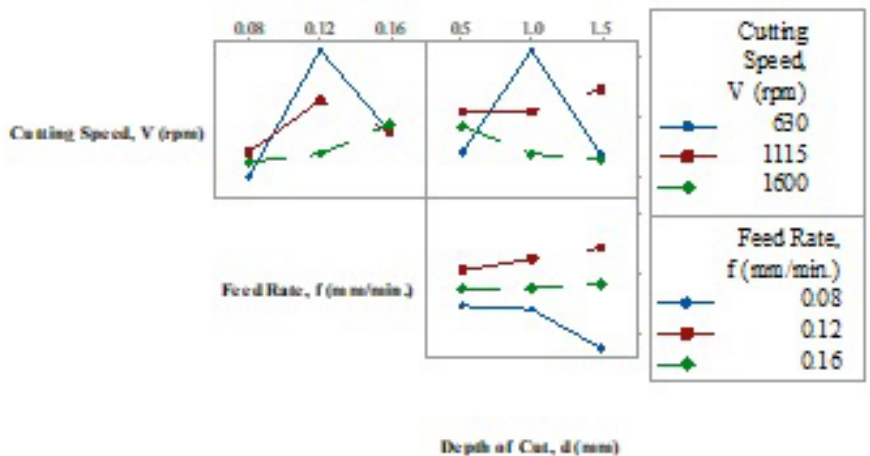

Fig. 6 Interaction Effect plots of PEEQ
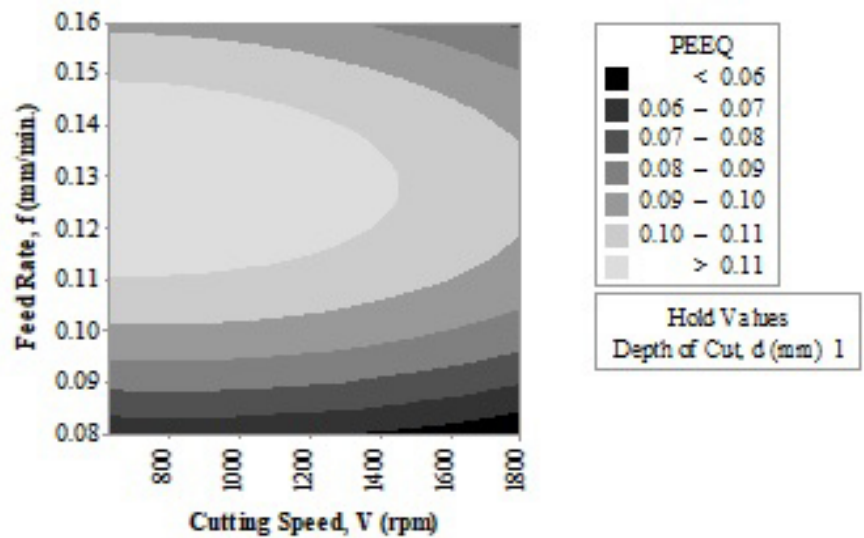

(a)

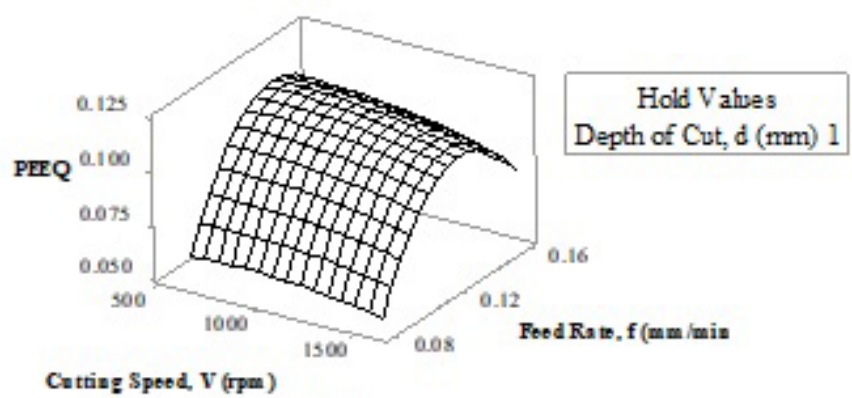

(b)

Fig. 7 (a) Contour and (b) Response Surface plots indicating the influence of $\mathrm{f}$ and $\mathrm{V}$ on PEEQ

Fig. 8 shows contour and response surface plots for PEEQ in relation to the machining parameters of $\mathrm{d}$ and $\mathrm{V}$, where f remains constant at its high level of $0.12 \mathrm{~mm} / \mathrm{min}$. PEEQ decreases with increases in depth of cut (d) and in cutting speed (V). This is because, as the cutting speed increases, more material removal takes place, which decreases the energy sufficient for failure due to shear. Consecutively, this reduces the cutting force, hence improving the surface finish. Therefore, the minimum PEEQ can be seen at a high value of $\mathrm{V}(1600 \mathrm{rpm})$ and high value of $\mathrm{d}(1.5 \mathrm{~mm})$. 
Fig. 9 shows contour and response surface plots for PEEQ in relation to the machining parameters of $d$ and $f$, where $V$ remains constant at its mean level of $1115 \mathrm{rpm}$. PEEQ decreases with increases in depth of cut (d) and with decreases in feed rate (f). At high values of feed rate, more volume of material is in contact with the work piece and hence more force is required to remove the material, which leads to the poor surface finish. Therefore, the minimum PEEQ can be seen at a high value of $d$ $(1.5 \mathrm{~mm})$ and low value of $\mathrm{f}(0.08 \mathrm{~mm} / \mathrm{min})$.

The optimization of PEEQ is shown in Fig. 10, in which each column represents factors. In each cell, the variation of the PEEQ is plotted against one of the parameters, keeping all other parameters constant. The goal for the response PEEQ is minimum, predicted PEEQ value (y) at current (optimal) parameter levels and desirability are shown at the left of the row. At the top of each column, high, current and low parameter settings are displayed.
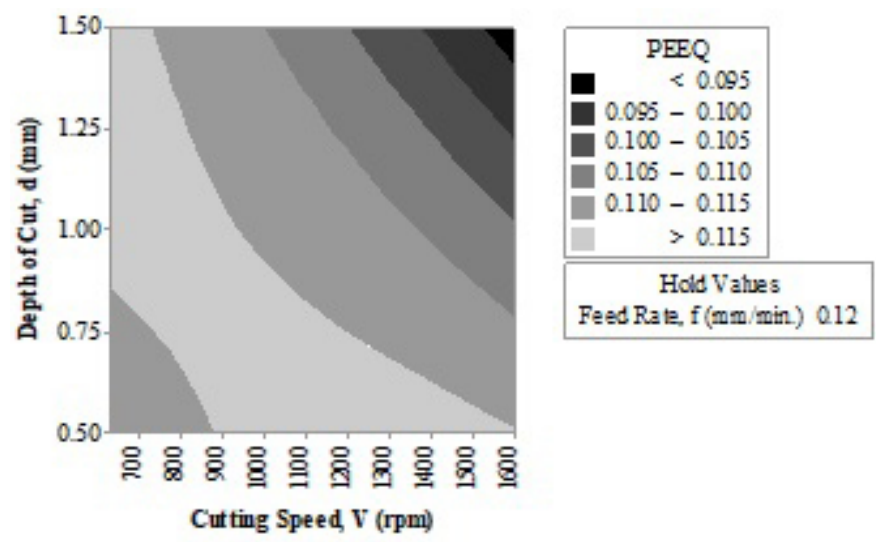

(a)

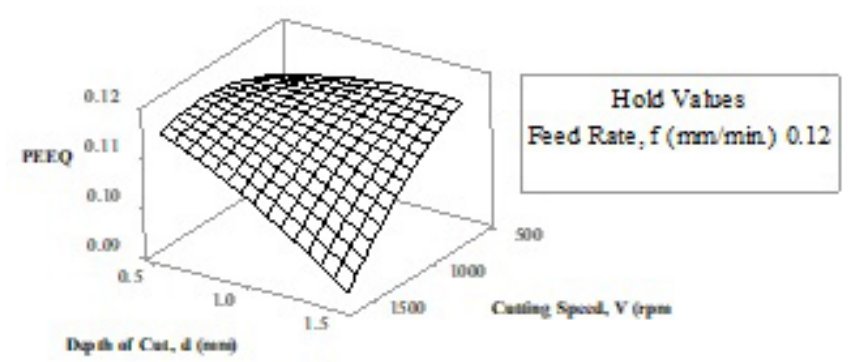

(b)

Fig. 8 Contour and Response Surface plots indicating the influence of $d$ and $\mathrm{V}$ on PEEQ

\section{Conclusions}

A detailed numerical model is developed to accurately predict the surface finish of Al 6061 - T6 alloys during orthogonal turning. Due to the time consuming and laborious, and huge cost of machining, only a less number of experiments/trails were performed. The developed model is then validated using the experimental results and the same numerical model is then further used to find the results for the remaining trails, for the different combinations of machining parameters. Using the Minitab software, ANOVA table were prepared for the response, by adopting central composite design (CCD). A full quadratic model was fitted to the responses using regression analysis. Using the concepts of individual desirability functions, the optimization of orthogonal turning process have studied for PEEQ. Hence, in this paper, a very beneficial novel idea is proposed for a manufacturing system, exclusively for turning process, for predicting the surface finish from the PEEQ values.
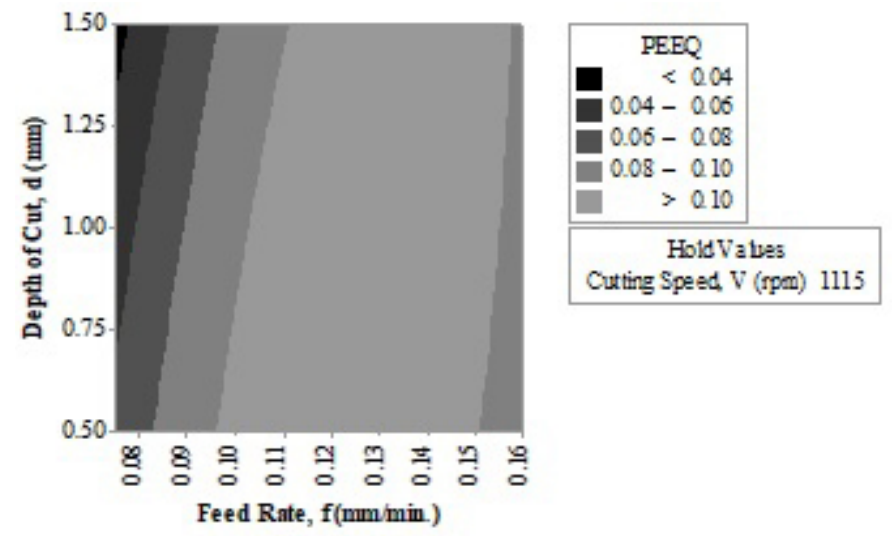

(a)

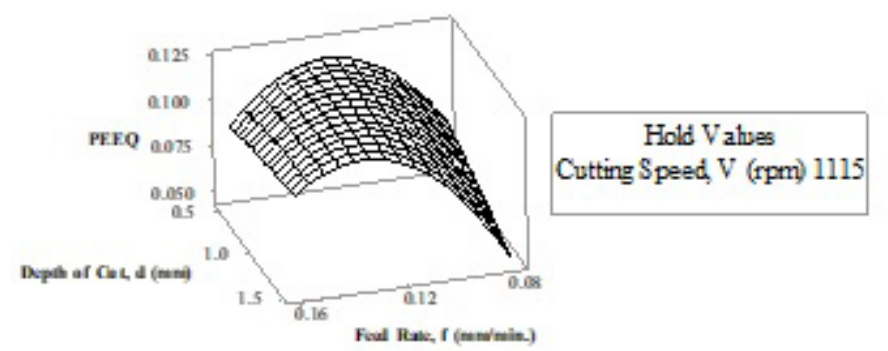

(b)

Fig. 9 Contour and Response Surface plots indicating the influence of $f$ and $d$ on PEEQ

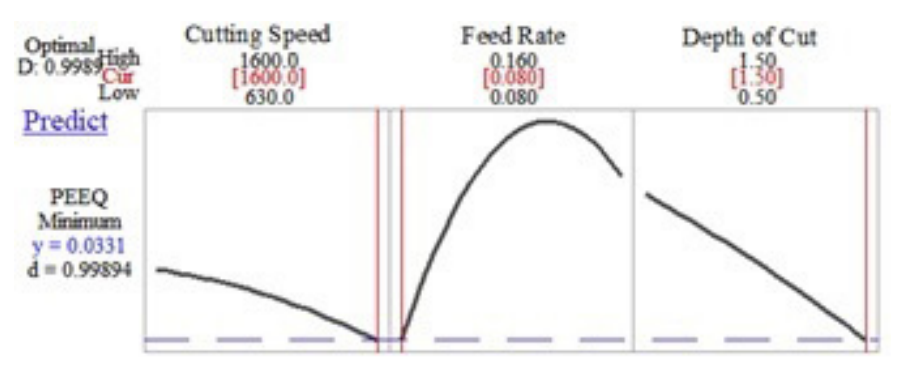

Fig. 10 Response optimization results of PEEQ 
Following are the important findings of this study:

- It was found that, feed rate (f) was the most predominant factor for PEEQ than the other parameters considered in this study.

- Surface finish increases as the cutting speed increases, since more material removal takes place, which decreases the energy sufficient for failure due to shear. Consecutively, this reduces the cutting force, hence improving the surface finish.

- At low values of feed rate, less volume of material is in contact with the work piece and less force is required to remove the material, which leads to the good surface finish.

- For minimum PEEQ, i.e. for best surface finish, the following combinations can be used:

$\mathrm{V}=1600 \mathrm{rpm}, \mathrm{f}=0.08 \mathrm{~mm} / \mathrm{min}, \mathrm{d}=1 \mathrm{~mm}$

$\mathrm{V}=1600 \mathrm{rpm}, \mathrm{f}=0.12 \mathrm{~mm} / \mathrm{min}, \mathrm{d}=1.5 \mathrm{~mm}$

$\mathrm{V}=1115 \mathrm{rpm}, \mathrm{f}=0.08 \mathrm{~mm} / \mathrm{min}, \mathrm{d}=1.5 \mathrm{~mm}$.

- Following combination of machining parameters leads to the optimized cutting condition, i.e. for a minimum value of PEEQ or for better or excellent surface finish. $\mathrm{V}=1600 \mathrm{rpm}, \mathrm{f}=0.08 \mathrm{~mm} / \mathrm{min}, \mathrm{d}=1.5 \mathrm{~mm}$.

\section{References}

[1] Somashekara, H. M., Swamy, N. L. "Optimizing Surface Roughness in Turning Operation Using Taguchi Technique and ANOVA." International Journal of Engineering Science and Technology. 4(05), pp. 1967-1973. 2012.

[2] Rajpoot, B. S., Moond, D. R., Shrivastava, S. "Investigating the Effect of Cutting Parameters on Average Surface Roughness and Material Removal Rate during Turning of Metal Matrix Composite Using Response Surface Methodology." International Journal on Recent and Innovation Trends in Computing and Communication. 3, pp. 241-247. 2015.

[3] Hasçalık, A., Çaydaş, U. "Optimization of turning parameters for surface roughness and tool life based on the Taguchi method." The International Journal of Advanced Manufacturing Technology. 38(9-10), pp. 896-903. 2008.

https://doi.org/10.1007/s00170-007-1147-0

[4] Lodhi, B. K., Shukla, R. "Experimental Analysis on Turning parameters for Surface roughness and MRR." Journal of Emerging Technologies and Innovative Research. 1, pp. 554-557. 2014.
[5] Adibi-Sedeh, A. H., Vaziri, M., Pednekar, V., Madhavan, V., Ivester, R. "Investigation of the Effect of Using Different Material Models on Finite Element Simulations of Machining." In: Proceedings of the 8th CIRP International Workshop on Modeling of Machining. pp. 215-224. 2005.

[6] Choudhury, I. A., El Baradie, M. A. "Surface roughness prediction in turning of high-strength steel by factorial design of experiments." Material Processing Technology. 67, pp. 55-61. 1997.

https://doi.org/10.1016/S0924-0136(96)02818-X

[7] Suresh, P. V. S., Venkateswara Rao, P., Desmukh, S. G. "A genetic algorithmic approach for optimization of the surface roughness prediction model." International Journal of Machine Tools and Manufacture. 42, pp. 675-680. 2002.

https://doi.org/10.1016/S0890-6955(02)00005-6

[8] Nalbant, M., Gökkaya, H., Sur, G. "Application of Taguchi method in the optimization of cutting parameters for surface roughness in turning." Materials and Design. 28, pp. 1379-1385. 2007.

https://doi.org/10.1016/j.matdes.2006.01.008

[9] Prakash Marimuthu, K., Krishnakumar, P., Rameshkumar, K., Ramachandran, K. I. "Finite element simulation of effect of residual stresses during orthogonal machining using ALE approach." International Journal of Machining and Machinability of Materials. 14, pp. 213-229. 2013.

https://doi.org/10.1504/IJMMM.2013.056363

[10] Ramesh, A., Sumesh, C. S., Abhilash, P. M., Rakesh, S. "Finite Element Modelling of Orthogonal Machining of Hard to Machine Materials." International Journal of Machining and Machinability of Materials. 17, pp. 543-568. 2015.

https://doi.org/10.1504/IJMMM.2015.073725

[11] Chen, G., Ren, C., Yang, X., Jin, X., Guo, T. "Finite element simulation of high-speed machining of titanium alloy (Ti-6Al-4V) based on ductile failure model." The International Journal of Advanced Manufacturing Technology. 56, pp. 1027-1038. 2011.

https://doi.org/10.1007/s00170-011-3233-6

[12] Ducobu, F., Rivière-Lorphèvre, E., Filippi, E. "Numerical contribution to the comprehension of saw-toothed Ti6Al4V chip formation in orthogonal cutting." International Journal of Mechanical Sciences. 81, pp. 77-87. 2014.

https://doi.org/10.1016/j.ijmecsci.2014.02.017 